\title{
PERCEPÇÃO DOS TRABALHADORES DE UM HOSPITAL PSIQUIÁTRICO SOBRE A ENFERMAGEM*
}

Dayane Carla Borille ${ }^{1}$, Marcio Roberto Paes², Tatiana Brusamarello ${ }^{3}$, Mariluci Alves Maftum ${ }^{4}$, Rita de Cássia Chamma $^{5}$, Maria Ribeiro Lacerda ${ }^{6}$

RESUMO: Pesquisa exploratória e de caráte qualitativo, desenvolvida em um hospital especializado em Psiquiatria no Paraná, que teve como objetivo apreender a percepção dos trabalhadores de um hospital psiquiátrico sobre a Enfermagem. Participaram 150 trabalhadores, sendo 80 da equipe de enfermagem, 14 outros profissionais, e 56 da equipe de apoio. Os dados foram obtidos através de encontros sustentados pelo Método do Arco de Maguerez e submetidos à análise temática. Da análise final emergiram as categorias temáticas: Profissão e ciência do cuidado, Prática reflexiva, Profissão de vocação e Trabalho em equipe. Os sujeitos ressaltaram o aspecto prático da Enfermagem e sua relação com o modelo biomédico, o tecnicismo e o cuidado humano. Concluiu-se que a prática da Enfermagem enseja aos sujeitos reflexões sobre suas ações profissionais e pessoais, proporcionando condições para atuar com vistas à melhoria dos cuidados voltados ao ser humano. PALAVRAS-CHAVE: Prática profissional; Equipe de assistência ao paciente; Cuidados de enfermagem.

\section{PSYCHIATRIC HOSPITAL WORKERS' PERCEPTIONS ON NURSING}

\begin{abstract}
This exploratory and qualitative research was developed in a hospital specialized in Psychiatry in Paraná State, and aimed to apprehend the psychiatric hospital workers' perception on nursing. Participants were 150 employees, 80 of them belong to the nursing staff, 14 were other professionals and 56 of the support staff. Data were collected through meetings supported by the Maguerez Arch Method and analyzed by the thematic analysis technique. Emerged themes: profession and science of caring, reflective practice, vocation and profession of teamwork. The participants emphasized the practical aspect of nursing and its relationship to the biomedical model, the technicality, and humane care. It was concluded that the practice of nursing entails subjects to reflections on their professional and personal actions, providing conditions to act in order to improve the human-oriented care.
\end{abstract}

KEYWORDS: Professional practice; Patient care team; Nursing.

\section{PERCEPCIÓN DE LOS TRABAJADORES DE UN HOSPITAL PSIQUIÁTRICO ACERCA DE LA ENFERMERÍA}

RESUMEN: Investigación exploratoria de carácter cualitativo desarrollada en un hospital especializado en Psiquiatría en Paraná, que tuvo como objetivo aprehender la percepción de los trabajadores de un hospital psiquiátrico acerca de la Enfermería. Participaron 150 trabajadores, siendo 80 del equipo de enfermería, 14 otros profesionales y 56 del equipo de apoyo. Los datos fueron obtenidos en encuentros por medio del Método del Arco de Maguerez y sometidos al análisis temático. Del análisis final, surgieron las categorías temáticas: Profesión y ciencia del cuidado, Práctica reflejiva, Profesión de vocación y Trabajo en equipo. Los sujetos resaltaron el aspecto práctico de la Enfermería y su relación con el modelo biomédico, el tecnicismo y el cuidado humano. Se concluye que la práctica de la Enfermería incita la reflexión de los sujetos acerca de sua acciones profesionales y personales, proporcionando condiciones para actuar con vistas a la mejoría de los cuidados al ser humano.

PALABRAS CLAVE: Práctica profesional; Equipo de asistencia al paciente; Cuidados de enfermería.

\footnotetext{
*Artigo original baseado na dissertação "Construção de marco de referência para o cuidado em saúde mental com a equipe de um hospital psiquiátrico” do Programa de Pós-Graduação em Enfermagem da Universidade Federal do Paraná-PPGENF-UFPR, apresentada em 2008. ${ }^{1}$ Enfermeira. Mestre em Enfermagem. Membro do Núcleo de Estudos, Pesquisa e Extensão do Cuidado Humano de Enfermagem-NEPECHE. ${ }^{2}$ Enfermeiro do Hospital de Clínicas da UFPR. Doutorando em Enfermagem pelo PPGENF-UFPR. Membro do NEPECHE. ${ }^{3}$ Enfermeira. Mestranda em Enfermagem do PPGENF-UFPR. Bolsista CAPES. Membro do NEPECHE.

${ }^{4}$ Enfermeira. Doutor em Enfermagem. Vice-Coordenador e docente do PPGENF-UFPR. Vice-Líder do NEPECHE.

${ }^{5}$ Enfermeira. Doutor em Enfermagem. Docente visitante do PPGENF-UFPR. Membro do Conselho Federal de Enfermagem. ${ }^{6}$ Enfermeira. Doutor em Enfermagem. Coordenador e docente do PPGENF-UFPR. Líder do NEPECHE.
}

\section{Autor correspondente:}

Mariluci Alves Maftum.

Universidade Federal do Paraná

R. João Clemente Tesseroli, 90 - 81520-190 - Curitiba-PR-Brasil

E-mail:maftum@ufpr.br 


\section{INTRODUÇÃO}

A atenção à saúde no Brasil, através do Sistema Único de Saúde (SUS), representa uma das mais avançadas propostas e ações em saúde no mundo, haja vista que organizada, considerando seus pressupostos de integralidade, universalidade e equidade, pretende atender de maneira humanística as necessidades da comunidade. Assim, as profissões da área da saúde devem formar profissionais para exercer suas atividades em consonância com os preceitos citados, a fim de alcançar a excelência na qualidade do cuidado, levando em consideração a realidade dos usuários ${ }^{(1)}$.

Na perspectiva contemporânea, uma profissão deve contemplar critérios de universalidade, racionalidade, autoridade e competência no seu campo específico. Portanto, suas características devem englobar: um conceito de missão aberto a trocas; domínio teórico de conhecimento; capacidade de resolver problemas; uso de conhecimento teórico; contínua busca de visibilidade por seus membros; educação formal; sistema de credenciamento para certificar competência; reforço legal de norma profissional; prática ética; penalidades contra prática antiéticas e incompetentes; aceitação pública; distinto rol que diferencie trabalho profissional de vocação e que permita uma prática autônoma a serviço da sociedade ${ }^{(1-2)}$.

A Enfermagem, dentre as demais profissões, tem a singularidade de ter o cuidado como sua essência. Estudiosos e profissionais a consideram como ciência e arte que imprimem à sua prática caráter específico, que possibilita a expressão diferenciada na equipe de saúde. Assim, ser ciência para a Enfermagem envolve trabalhar com um corpo cumulativo de conhecimento científico, derivado das ciências físicas, biológicas e do comportamento, constituindo, portanto, um ramo do corpo de conhecimento que o diferencia daquele de outras disciplinas. O caráter de arte está inserto na atividade profissional quando o enfermeiro faz aplicação prática da ciência da Enfermagem e opta pela melhor base teórica que sustente suas ações ${ }^{(3)}$.

O cuidado é o ideal moral da Enfermagem e tem a ele associado um chamamento que resgata $o$ legado de Florence Nightingale. O enfermeiro deve ser guiado pelo senso crítico e pelo compromisso ético de servir o outro, tendo no íntimo a sensação de ter sido chamado para essa função. Ao considerar o cuidado como ideal de profissão, transcende-se a um chamado vocacional no sentido do senso comum e possibilita que a prática da Enfermagem seja imbuída de caráter de chamamento ao servir a humanidade no cuidado e proteção com a vida ${ }^{(4-6)}$.

Uma forte característica da Enfermagem como profissão é a capacidade que seus profissionais possuem de desenvolver ações refletindo sobre elas. Esse olhar reflexivo resulta em atenção ao ambiente de cuidado, ao ser cuidado e tudo quanto permeia a profissão, diferentemente do modo como se via outrora. Tendo por "base novos insights, novas perspectivas, pode-se agir de forma diferente" e, assim, ao refletir sobre a sua prática, o profissional de enfermagem tem a possibilidade de transformá-la constantemente e, dessa forma, agir em consonância às necessidades do ser humano ${ }^{(7: 141)}$.

Por compreender que os profissionais de enfermagem despedem maior tempo de cuidado aos pacientes, em relação aos demais profissionais da área da saúde mental; que o contato com o paciente e família é intensificado dada a sua especificidade de prestação de cuidados; pela premissa de que seu trabalho acontece em equipe e que o compartilhar as impressões e informações sobre o paciente potencializa as condições para se estabelecer um plano terapêutico efetivo, justifica-se este estudo com a questão norteadora: como os trabalhadores atuantes em hospital psiquiátrico percebem a Enfermagem? E como objetivo: apreender a percepção dos trabalhadores de um hospital psiquiátrico sobre a Enfermagem.

\section{METODOLOGIA}

Pesquisa qualitativa, exploratória, desenvolvida em uma instituição psiquiátrica de um município do Estado do Paraná, em 2008.

Todos os trabalhadores da instituição (316) foram convidados a participar do estudo, sendo que 150 aceitaram, os quais foram divididos em grupos profissionais: Equipe de enfermagem (5 enfermeiros, 1 técnico e 74 auxiliares de enfermagem); Grupo técnico ( 2 médicos, 4 psicólogos, 4 terapeutas ocupacionais, 3 assistentes sociais, 1 fisioterapeuta); Grupo de apoio (4 auxiliares administrativos, 6 agentes operacionais, 1 telefonista, 3 agentes de manutenção, 2 motoristas, 1 segurança, 39 copeiras e auxiliares de serviços gerais.

$\mathrm{Na}$ instituição existem quatro turnos de trabalho, dois diurnos e dois noturnos e, para que todos os trabalhadores pudessem participar dos encontros, foram formados 8 grupos, sendo dois por turno de 
trabalho. Enquanto parte dos trabalhadores participava dos encontros, a outra mantinha suas atividades e, na semana seguinte, os grupos se alternavam. Os encontros ocorreram com cronograma prévio, em sala determinada pela direção do hospital.

A obtenção dos dados ocorreu através de encontros sustentados pelo Método do Arco de Mague$\mathrm{rez}^{(8)}$, sendo problematizado o tema "Enfermagem". Foram distribuídas folhas de papel em branco para cada um dos participantes. Em seguida, foi solicitado que refletissem a respeito da realidade que vivenciavam no cotidiano do seu trabalho em saúde mental na instituição, e complementassem a afirmativa: "Enfermagem para mim é ..."

Cada participante fez registros mediante a escrita, e alguns com desenhos complementando a ideia, e na sequência, apresentavam ao grupo o que haviam produzido, seguido das discussões. Os relatos e as discussões foram gravados em fita cassete e complementados pelas anotações em diário de campo do pesquisador. Após a atividade, procedeu-se a teorização à Luz da Teoria das Relações Interpessoais de Joyce Travelbee ${ }^{(9-10)}$. Os dados foram organizados em categorias temáticas, de acordo com a proposta de análise temática ${ }^{(11)}$.

Para garantir o sigilo e anonimato dos participantes, e devido à diversidade de enquadramento funcional na instituição, os relatos estão identificados como: Enfermagem (Enfermeiro, Técnico e Auxiliar de Enfermagem); Técnico (Psicólogo, Médico, Terapeuta Ocupacional, Fisioterapeuta, Assistente Social); e Apoio para designar os demais trabalhadores.

O projeto foi aprovado pelo Comitê de Ética em Pesquisa do Setor de Ciências da Saúde da Universidade Federal do Paraná (UFPR), com a Inscrição 2035.0.000.091.0.

\section{RESULTADOS}

Da análise final dos dados, emergiram as categorias temáticas: Profissão e ciência do cuidado; Prática reflexiva; Profissão de vocação; e Trabalho em equipe.

\section{Profissão e ciência do cuidado}

Os relatos dos sujeitos salientaram os aspectos do cuidado integral aos pacientes, aplicação de conhecimento e práticas específicas que contemplam a subjetividade e individualidade do ser humano com vistas à autonomia. Eles caracterizaram a Enfermagem como ciência que sistematiza e organiza sua prática no desenvolvimento do cuidado:

[...] uma profissão que presta assistência ao ser humano, de forma integral, para minimizar os conflitos, oportunizar melhores condições de vida, aplicando conhecimentos e práticas de caráter preventivo, curativo e de reabilitação, respeitando a dignidade e o valor do ser humano. (Enfermagem 7)

[...] uma ciência, porque estuda as maneiras e métodos de realizar cuidados de enfermagem com os clientes [...]. (Enfermagem 26)

[...] prática organizada da assistência à saúde ou resgate desta, respeitando as individualidades, culturas e a intimidade de cada ser assistido, de maneira a estimulá-lo à conquista de sua autonomia, respeitando ao mesmo tempo os seus limites. É minimizar o sofrimento, utilização de técnicas aliadas à humanização, resgatar autonomia para o autocuidado. (Enfermagem 39)

[...] a profissão ou função responsável por cuidar da saúde mental e física das pessoas. Abrange tanto o tratamento quanto a prevenção das doenças. Está ligada diretamente ao bem-estar físico e mental das pessoas [...]. (Técnico 2)

[...] uma profissão que os profissionais são capacitados para atender os pacientes com problemas psiquiátricos, que precisam de ajuda de toda a equipe. Para ajudar o paciente e família a fazer o tratamento completo. (Apoio 6)

[...] é ter cuidado com os pacientes. Tem pacientes que internam muito ruins e saem do hospital, cheios de esperança para continuar suas vidas lá fora [...]. (Apoio 15)

Embora os relatos anteriores tenham correlacionado a Enfermagem com o cuidado integral, o respeito à subjetividade e às questões culturais do paciente, nos relatos a seguir, evidenciou-se a ênfase aos aspectos biologicista e tecnicista e aos cuidados centrados no corpo da pessoa, mediante o uso de técnicas:

A Enfermagem auxilia o paciente em quase tudo quando ele está impossibilitado. [...] na higiene 
corporal, oral, administração de medicamento [...]. (Enfermagem 68)

Enfermagem é tudo: dar medicação, banho se for necessário, verificar sinais vitais [...]. (Enfermagem 56)

A Enfermagem no hospital é muito importante, pois ela presta cuidados aos pacientes, como banho, curativos, medicamentos [...]. (Enfermagem 30)

[...] é dar medicação aos pacientes internados, a qual deve seguir exatamente o critério médico, sempre com muita responsabilidade, cumprir horário. (Apoio 26)

Nos dados a seguir, percebe-se a presença da polaridade no processo de reabilitação psicossocial, em que de um lado há a referência de se colocar limites para que, consequentemente, o paciente venha melhorar do quadro agudo de transtorno mental e, do outro lado, a ênfase para que ele consiga exercer sua autonomia. Isso é percebido na fala do sujeito Enfermagem 11 que, ao discorrer sobre a sua profissão, especifica-a na área de saúde mental, relacionando-a com imposição de limites com intuito de proporcionar autonomia aos pacientes; o sujeito Enfermagem 56 refere que a Enfermagem objetiva dar suporte às necessidades psicossociais aos indivíduos:

A Enfermagem em saúde mental é colocar limites no paciente para voltar à realidade e ter sua autonomia [...]. (Enfermagem 11)

[...] visa atender às necessidades biopsicossociais. (Enfermagem 56)

\section{Prática reflexiva}

Os participantes enfocaram que a Enfermagem é uma prática que enseja repensar sua condição humana, promove a autorrealização e o autoaprendizado dos profissionais, permitindo a estes sentir-se úteis e aprender com o paciente. Eles encontram respaldo para o crescimento e fortalecimento pessoal, a partir da relação com o paciente e o reconhecimento do seu sofrimento:

[...] é autoaprendizado, realização como ser humano diante de tanto sofrimento até mesmo na alta, de atendimento adequado, situação familiar e social de cada um. (Enfermagem 47)
[...] é sempre um aprendizado novo. Nesta profissão, aprendi a valorizar a vida e não dar tanta importância para os problemas que surgem diariamente em minha vida. É trabalhando na Psiquiatria que realmente me encontrei e percebi que sou feliz. (Enfermagem 9)

[...] é realização pessoal e profissional, principalmente porque trata de vidas. É autoaprendizado [...]. (Enfermagem 29)

[...] aprendo muito no contato com as pessoas que estão doentes. Fico mais forte para resolver meus sofrimentos do dia a dia [...]. (Enfermagem 66)

Enfermagem precisa ter e ser ouvido. Ter e ser respeitado e aprender a respeitar o sofrimento, resgate social; aprender a falar de si; organização pessoal; consciência e aprender a lidar com sua doença; não mentir [...]. (Enfermagem 71)

\section{Profissão de vocação}

Os relatos dos participantes do grupo de apoio evidenciam a concepção de Enfermagem como profissão de vocação, de servir ao próximo, de dom especial, de doação pautada no ideal de amor, dedicação, paciência e que não mede esforços para cuidar do doente. Também há a compreensão, exemplificada por Apoio 16, de que é uma profissão que auxilia o médico, mas que, por outro lado, necessita ter conhecimento:

O profissional da Enfermagem é a pessoa mais próxima do paciente, o auxiliar indispensável do médico. [...] observo que requer muita dedicação para melhor servir [...]. (Apoio 39)

Enfermagem é ter conhecimento, muita dedicação para cuidar das pessoas doentes, seja qual for a enfermidade. Dar tudo de si para aliviar o sofrimento do paciente. É muita dedicação, profissionalismo, amor à profissão, paciência, determinação. (Apoio 16)

[...] é uma grande responsabilidade, é doação, carinho, doar assistência a quem precisa, amor, paciência. (Apoio 2)

Antes de ser profissão é um dom especial de manifestação de amor ao próximo. (Apoio 9) 


\section{Trabalho em equipe}

Os participantes dos grupos Técnico e Apoio destacaram que para eles a Enfermagem é uma profissão que envolve muita responsabilidade, e a percebem como integrante da equipe multiprofissional. Referiram que os profissionais de Enfermagem são indispensáveis, pois são eles que permanecem maior tempo e mais próximos do paciente. Isso oferece condições de observar as manifestações de comportamento dos pacientes, colaborar com a equipe no diagnóstico e estabelecimento do projeto terapêutico:

São estes profissionais que auxiliam, executam atividades diretamente e em tempo integral com os pacientes e são profissionais que integram a equipe multiprofissional. (Técnico 5)

Enfermagem atua frente às necessidades das pessoas que buscam atendimento em saúde, sempre numa perspectiva de integração e interação com outros profissionais ou disciplinas da área da saúde - na promoção à saúde, prevenção ou assistência básica ou especializada. (Técnico 1)

A Enfermagem é indispensável dentro da equipe [...]. É a pessoa mais próxima, durante maior tempo, portanto é quem vai perceber a mudança para melhor ou para pior do mesmo e ajudar os outros técnicos, colaborando muito no tratamento. É um trabalho de muita responsabilidade, importante, indispensável [...]. (Apoio 23)

\section{DISCUSSÃO}

A relação entre a Enfermagem e o cuidar é bastante nítida na fala dos sujeitos. O cuidado é intrínseco ao ser humano e desenvolvido pela humanidade milenarmente. Entretanto, o cuidado profissionalizado é a essência da Enfermagem e, para tanto, esta profissão deve ser instrumentalizada pelo conhecimento, habilidade, competências próprias e específicas, a fim de ser desenvolvida com excelência e qualidade ${ }^{(7)}$.

A característica tecnicista da Enfermagem, apontada pelos sujeitos, se deve ao modelo biomédico, fortemente arraigado na área da saúde, exercendo grande influência sobre as ações da Enfermagem. Nesse modelo, nota-se a fragmentação e o reducionismo do ser humano e, consequentemente, do cuidado. Contudo, a Enfermagem, nos últimos anos, vem se expandindo e consolidando como área científica. Dessa forma, tem subsidiado sua prática embasada em conhecimento próprio, construindo seu espaço profissional, com vistas à conjugação do saber e da prática que se distanciem da visão despersonalizante do ser humano, superação concretizada no ato de cuidar integral e humanamente ${ }^{(3,7,12-13)}$.

Cabe ressaltar que, em sua plenitude cuidadora, a Enfermagem atual expressa conhecimento voltado às atividades de pesquisa, à educação em saúde e à formação, no planejamento e gerenciamento das ações em saúde, na relação pessoa a pessoa, na comunicação terapêutica, e no respeito à integralidade do ser humano. Dessa maneira, sua atuação extrapola o desenvolvimento de procedimentos técnicos ${ }^{(7,13-15)}$. A amplitude da atuação da Enfermagem não representa rejeição aos aspectos técnicos, mas ênfase ao processo de interação entre o cuidador e o ser cuidado, a fim de oferecer mais qualidade às suas ações ${ }^{(7)}$.

Os sujeitos apontam que o cuidado de enfermagem em saúde mental busca dar autonomia aos pacientes com transtorno mental. Entretanto, devese compreender que a autonomia é a capacidade do indivíduo em conduzir sua própria vida, estipulando condições, formas e ordens de como organizá-la e enfrentar situações advindas do cotidiano. Para tanto, a autonomia, a autosuficiência e a independência não são sinônimos, portanto, não podem ser confundidos em sua aplicação na Enfermagem. As pessoas têm dependência umas das outras, o que as fazem seres de relacionamento e, assim, dificilmente, são autossuficientes. Dessa forma, a pessoa que acrescenta sua capacidade em relacionamento e trocas de experiência com as outras pessoas tem sua autonomia estendida ${ }^{(16)}$.

Na compreensão psicossocial, a autonomia do paciente com transtorno mental advém de sua condição em participar do próprio processo de tratamento e reabilitação, com direitos de opinar e dizer sobre o que entende como melhor para si. Essa visão se contrapõe àquela que perdurou por séculos e que ainda está presente na prática de muitos profissionais de saúde mental. Nessa concepção, o paciente era recebedor de procedimentos técnicos, por vezes iatrogênicos, como a contenção física, entendida como necessária para impor limites, e outras como o excesso de medicação e a proibição da expressão de seus sentimentos ${ }^{(16)}$.

Atualmente, com a evolução teórica-prática, na Enfermagem, o cuidar se estabelece entre outras ações pela relação interpessoal, em que equipe e paciente são envolvidos no contexto do cuidado e 
de aprendizagem, modificando comportamentos e atitudes para alcançar a melhor condição de saúde ${ }^{(10)}$. Destarte, o desenvolvimento dessa relação se fundamenta na observação do profissional sobre seus próprios comportamentos, sentimentos e atitudes, para se conhecer e aceitar seu potencial, capacidade e limitações. É pelo autoconhecimento e pela reflexão sobre o seu 'fazer', que o profissional de enfermagem em saúde mental poderá cuidar de forma eficiente das pessoas, utilizando-se da competência na relação interpessoal e com o ambiente em que vive ${ }^{(10,13)}$. Cada ser humano possui comportamentos específicos e maneiras diferentes de pensar; assim, a equipe de enfermagem deve compreender e acolher a singularidade e unicidade da pessoa com transtorno mental, a sua trajetória de vida, com vistas a planejar o cuidado de acordo com as suas necessidades ${ }^{(3,7,13)}$.

Contudo, mesmo a Enfermagem expandindo seu conhecimento e desenvolvendo suas ações embasadas teoricamente, nos relatos dos sujeitos evidenciou-se que perdura a concepção de Enfermagem como aquela desempenhada por religiosas entre os séculos V e XVIII. Esse período deixou como legado uma série de valores que, com o passar do tempo, foram aos poucos legitimados e aceitos pela sociedade como inerentes à Enfermagem. Dentre esses, estão a abnegação, o espírito de serviço, a subserviência e a obediência, entre outros, que conferiam à Enfermagem uma conotação de sacerdócio ${ }^{(17)}$. Esse imaginário presente no ambiente de prática da Enfermagem requer dos profissionais a responsabilidade na mudança desta visão para a de uma profissão com base científica, que possui corpo de conhecimento específico, integrante de uma equipe multiprofissional, e que tenha o cuidado como ideal moral da profissão ${ }^{(4-5)}$.

Estes fatos históricos tornaram-se determinantes e condicionantes na formação da imagem e identidade da Enfermagem em saúde mental pela sociedade, em âmbito macro, e na instituição de estudo, em âmbito micro. A identidade é concebida como algo formado ao longo do tempo, por meio de processos inconscientes e, em relação ao enfermeiro, podemos considerar que ela foi e está sendo formada na interação deste profissional com a sociedade, pois é construída no cotidiano do trabalho. Imagem é uma representação mental, impressões e posições que as pessoas apresentam em relação umas às outras. No que concerne à Enfermagem em saúde mental, a imagem pública do enfermeiro influencia sua prática, conforme demonstram os relatos dos trabalhadores integrantes Grupo de Apoio, que a relacionaram à doação, ao servir, a dom e a seguir ordens médicas ${ }^{(17)}$.

Os relatos dos participantes a respeito da importância do profissional de enfermagem na equipe multiprofissional e de sua proximidade com a pessoa com transtorno mental corroboram os estudos que destacam a Enfermagem como ligação entre a pessoa com transtorno mental e a equipe, por permanecer maior tempo com o paciente, observando, registrando, avaliando seu comportamento e suas relações. De fato, realizar estes registros e comunicar-se com a equipe pode contribuir para o planejamento do projeto terapêutico individual à pessoa com transtorno mental e/ ou para a definição do seu diagnóstico ${ }^{(1,13,16)}$

A necessidade do trabalho multiprofissional e interdisciplinar decorre do fato de que o adoecer mental é um fenômeno complexo e, mesmo reconhecendose as competências disciplinares, é preciso assegurar o espaço de interconexão entre os saberes e práticas para dar conta, ao mesmo tempo, da singularidade e da complexidade do cuidado em saúde mental. A pessoa que adoece mentalmente, para ser cuidada na sua integralidade, necessita que isto aconteça com uma equipe multidisciplinar e interdisciplinar, pois seus problemas abrangem a saúde, o trabalho, a família, a habitação e, por vezes, a justiça $a^{(1,16,18)}$.

De acordo com as indicações aprovadas na III Conferência Nacional de Saúde Mental ${ }^{(19)}$, a política de recursos humanos visa o trabalho interdisciplinar e multiprofissional, na perspectiva da construção de um novo trabalhador em saúde mental, atento e sensível aos diversos aspectos do cuidado, com olhar não fragmentado da pessoa com transtorno mental.

\section{CONSIDERAÇÕES FINAIS}

As recentes mudanças estruturais na área de saúde mental proporcionaram a formação do cuidado multiprofissional, no qual a Enfermagem está inserida. Assim, neste estudo, teve-se a intenção de se conhecer como os trabalhadores que atuam na área de saúde mental percebem a Enfermagem, visto que existe importância na compreensão e reconhecimento subjetivo do significado dessa profissão, uma vez que seus agentes são transformadores sociais para o desenvolvimento de uma prática que atenda as necessidades de saúde da comunidade.

A compreensão sobre a Enfermagem foi descrita pelos participantes como abrangendo questões relativas à prática da enfermagem e, especificamente, 
na área de saúde mental, por exemplo, ao referirem a autonomia e reabilitação psicossocial da pessoa com transtorno mental. Também é uma profissão que requer habilidades e competências específicas para seu exercício, entre elas responsabilidade, respeito, consciência do seu papel, dedicação e amor. Chamou-nos a atenção o fato de que os profissionais dos grupos Enfermagem e Técnicos enfatizaram a Enfermagem como sendo profissão e ciência que atua na área da saúde em nível primário, secundário e terciário da atenção. Ela é considerada ciência para os profissionais de enfermagem deste estudo, que a caracterizam como profissão que desenvolve conhecimento próprio e constrói ciência. Contudo, os trabalhadores do grupo Apoio expressaram mais sobre os aspectos relacionados à vocação, como ato de caridade, de dedicação e dom, tendo uma percepção sob o ponto de vista do senso comum.

Os achados deste estudo são consonantes à mobilização existente nos dias de hoje, em que os enfermeiros buscam fortalecer sua identidade como profissionais com autonomia e cientificidade. Pelas reflexões e teorizações ocorridas, os trabalhadores da instituição tiveram a oportunidade de conhecer mais sobre a Enfermagem e ampliar suas visões sobre essa profissão, o que resulta em maior visibilidade à Enfermagem na área de saúde.

\section{REFERÊNCIAS}

1. Saupe R, Cutolo LRA, Wendhausen ÁLP, Benito GAV. Competência dos profissionais da saúde para o trabalho interdisciplinar. Interface - Comunicação, Saúde e Educação. 2005;9(18):521-36.

2. Erdmann AL, Rodrigues ACRL, Koerich MS, Backes DS, Drago LC, Klock P. O olhar dos estudantes sobre sua formação profissional para o Sistema Único de Saúde. Acta Paul Enferm. 2009;22(3):288-94.

3. Pires D. A enfermagem enquanto disciplina, profissão e trabalho. Rev Bras Enferm. 2009;62(5):739-44.

4. Lacerda MR. Enfermagem: uma maneira própria de ser, estar, pensar e fazer. Rev Bras Enferm. 1998;51(2):207-216.

5. Watson. J. Enfermagem: ciência humana e cuidar uma teoria de enfermagem. Tradução de João Agnes. Lourdes: Lusociência; 2002.

6. Mathias JJS. Cuidado transpessoal de enfermagem ao familiar cuidador da criança com neoplasia: um marco referencial [dissertação]. Curitiba (PR): Universidade
Federal do Paraná; 2007.

7. Waldow VR. Momento de cuidar: momento de reflexão na ação. Rev Bras Enferm. 2009;62(1):140-5.

8. Bordenave JD, Pereira AM. Estratégias de ensinoaprendizagem. 25 a ed. Petrópolis: Vozes; 2004.

9. Chistóforo BEB, Zagonel IPS, Carvalho DS. Relacionamento enfermeiro-paciente no préoperatório: uma reflexão à luz da Teoria de Joyce Travelbee. Cogitare Enferm. 2006;11(1):55-60.

10. Travelbee J. Intervencion en enfermeira psiquiátrica: el processo de la relacion de persona a persona. $2^{\mathrm{a}}$ ed. OPAS/OMS. Colômbia; 1979.

11. Minayo MCS. O desafio do conhecimento: pesquisa qualitativa em saúde. $8^{\mathrm{a}}$ ed. São Paulo: Hucitec; 2004.

12. Budo MLD, Beck CLC, Mostardeiro SCTS. Interfaces do cuidado, da educação e do trabalho na enfermagem. Santa Maria: Facos-UFSM; 2005.

13. Borille DC. Construção de marco de referência para o cuidado em saúde mental com a equipe de um hospital psiquiátrico [dissertação]. Curitiba (PR): Universidade Federal do Paraná; 2007.

14. Brusamarello T, Guimarães AN, Paes MR, Borba LO, Borille DC, Maftum MA. Cuidado de enfermagem em saúde mental ao paciente internado em hospital psiquiátrico. Cogitare Enferm. 2009;14(1):79-84.

15. Stefanelli MC, Carvalho EC, organizadores. A comunicação nos diferentes contextos da enfermagem. Barueri: Manole; 2005.

16. Pereira MAO. A reabilitação psicossocial no atendimento em saúde mental: estratégias em construção. Rev Latino-Am Enfermagem. 2007;15(4):658-64.

17. Nauderer TM, Lima MADS. Imagem da enfermeira: revisão de literatura. Rev Bras Enferm. 2005;58(1):4-7.

18. Schneider JF, Souza JP, Nasi C, Camatta MW, Machineski GG. Concepção de uma equipe de saúde mental sobre interdisciplinaridade. Rev Gaúch Enferm. 2009;30(3):397-405.

19. Conselho Nacional de Saúde (BR). Comissão Organizadora da III CNSM. Relatório Final da III Conferência Nacional de Saúde Mental. 11 a 15 de dezembro de 2001. Brasília (DF); 2002. 